\title{
Gamifying health: Using video games for obesity and diabetes interventions
}

\section{Westerly Luth}

\section{University of Alberta}

Video games are a common recreational activity for Canadians of all ages: $59 \%$ of Canadians play computer or video games ${ }^{1}$ and the average Canadian gamer is 33 years old. ${ }^{1}$ Rather than being considered an antagonist in the fight against obesity and diabetes, video games can be used to support healthy behaviour such as improving nutrition and encouraging exercise; two of the most important modifiable risk factors for some forms of diabetes and obesity. ${ }^{2}$ Video games designed for health education have increased player knowledge, changed health attitudes, and changed health behaviours. ${ }^{3}$ For example, children with Type 1 diabetes who played the interactive diabetes educational game Packy \& Marlon ${ }^{\circledR}$ had higher diabetes-related self-efficacy, self-care behaviours and fewer unscheduled urgent doctor visits. ${ }^{4}$ Active games (such as Wii ${ }^{\mathrm{TM}}$ Sports, and Just Dance ${ }^{\mathrm{TM}}$ ) have demonstrated positive effects on gamer health: players experience increased metabolic activity compared to sedentary game play. ${ }^{5}$ Although exciting, we have yet to demonstrate that educational and active video games can compete with conventional games for player's attention outside experimental conditions.

Video games have been used for educational interventions, but another aspect to obesity and diabetes interventions is motivating people to begin and continue healthy behaviours. Gamification is the application of the motivational elements that make video games "fun" to non-video game applications, ${ }^{6}$ like obesity and diabetes interventions. Some of the gaming elements that can be used are: the competitive and supportive social experience within and around the game, ${ }^{7}$ the challenge presented ${ }^{7}$ and the fulfilment of fantasy. ${ }^{7}$ Another element is clearly defined feedback rewards that signal, perhaps more obviously and tangibly than other aspects of a gamer's life, that the player's achievements are acknowledged and worthwhile. ${ }^{7}$ Not all of these elements are used in every gamification strategy and other video games elements are used as well. Gamification interventions could be implemented on common mobile devices such as cell phones and smart phones. Gamification principles have been applied to consumer reward programs and on social media sites to encourage users to engage with their services. But what would gamified obesity and diabetes interventions look like?

The Humana American Horsepower Challenge used some of these elements in their intervention in secondary schools to increase walking among students. Children at participating schools walked more, but commitment to the program declined after a few months. Pedometers automatically uploaded step counts to a website. ${ }^{8}$ Students unlocked ribbons and customizations by walking more ${ }^{8}$ (feedback). On the website, schools' avatars raced against each other ${ }^{9}$ (challenge). Critical errors, however, limited the intervention's success. The "game" did not allow students to interact with each other" (social interaction). The students' goal (to collectively walk more than other schools thereby winning a grant for their school) was predefined and the students did not feel invested in winning ${ }^{8}$ (challenge). Furthermore, slow school computers and pedometer malfunctions contributed to declines in students' engagement. ${ }^{8}$ Despite the shortcomings of the Horsepower challenge, more interventions like it are needed to determine how to successfully gamify health interventions.

Another intervention for Type 1 diabetes is Bayer's Didget $^{\circledR}$. This system integrates accurate self-monitoring of blood glucose with the handheld Nintendo DS ${ }^{\circledR}$ console. $^{9}$ Didget $^{\circledR}$ users have access to an online community (social interaction). Players who perform blood glucose tests throughout the day gain access to new levels and receive bonuses for consistent testing habits (feedback). ${ }^{9}$ Didget $^{\circledR}$ users can set personalized target range goals ${ }^{9}$ (challenge). Users thought Didget ${ }^{\circledR}$ was useful for the management of 
their diabetes, but studies need to be done comparing the effectiveness of the Didget $^{\circledR}$ system to other monitoring systems. ${ }^{9}$ Using various video game elements, the Didget $^{\circledR}$ system gamifies blood glucose self-monitoring, which may not be intrinsically motivating for many people with diabetes.

Despite these applications, gamification is not foolproof or easy. Research into quantifiable long-term outcomes of gamification interventions is needed to determine if gamification is feasible and cost-effective. Technical malfunctions, long-term maintenance and upgrade commitments are serious challenges to gamified interventions. A related concern that must be addressed is if the use of external gamification motivators will inhibit internal motivation to engage in healthy behaviour when the gamified intervention is discontinued..$^{10}$ Further research into video game elements and the particular strengths and pitfalls of specific elements in health intervention strategies must be done. Despite these challenges, gamification is worth exploring for new ways to engage with children and adults to encourage healthy behaviours.

Health researchers can learn about motivating people from video game developers. Challenge, fantasy, curiosity, competitive and supportive social networks, and feedback rewards are only some of the elements of video games that could be used to invigorate health interventions. Bold, creative collaboration between researchers, health care providers, video game developers and companies like Bayer to gamify health behaviours should be encouraged to find the limits of the application to gamification of health interventions for all ages.

\section{Acknowledgments}

Thank you to my family for their support, and my lab group for their encouragement.

\section{References}

1. Entertainment Software Association of Canada. 2011 Essential Facts about the Canadian computer and video game industry. Entertainment Software Association of Canada; 2011. [Accessed Mar 5, 2012]. Available from: http://www.theesa.ca/wp-content/uploads/2011/10/Essential-Facts-2011. pdf

2. World Health Organization. March 2011. Obesity and overweight Fact Sheet no. 311. Available from:http://www.who.int/mediacentre/factsheets/ fs311/en/index. html [Accessed Mar 20, 2012]

3. Baranowski T, Buday R, Thompson DI, Baranowski J. Playing for Real: Video games and stories for health-related behavior change. Am J Prev Med. 2008 Jan; 34(1): 74-82.

4. Brown SJ, Lieberman DA, Gemeny BA, Fan YC, Wilson DM, Pasta DJ. Educational video game for juvenile diabetes: Results of a controlled trial. Medical Informatics. 1997 Jan-Mar; 22(1): 77-89.

5. Graves L, Stratton G, Ridgers ND, Cable NT. Energy expenditure in adolescents playing new generation computer games. Br I Sports Med. 2008 42:592-594

6. Deterding S, O'Hara K, Sicart M, Dixton D, Nacke L. Gamification: Using game design elements in non-gaming contexts. In Proceedings of the 2011 Annual Conference Extended Abstracts on Human Factors in Computing Systems; 2011; Vancouver, BC, Canada. P. 2425-2428.

7. Dickey MD. Engaging by Design: How engagement strategies in popular computer and video games can inform instructional design. ETR\&D. 2005; 53(2): 67-83.

8. Eiriksdottir E, Xu Y, Miller A, Poole E, Catrambone R, Kestranek D et al. Assessing health games in secondary schools: An investigation of the American Horsepower Challenge 2009-2010. Atlanta (GA): Georgia Institute of Technology; 2011 Jul. $147 \mathrm{p}$.

9. Klingensmith GJ, Aisenberg J, Kaufman F, Malvorson M, Cruz E, Riordan ME et al. Evaluation of a combined blood glucose monitoring and gaming system (Didget ${ }^{\circledR}$ ) for motivation in children, adolescents and young adults with type 1 diabetes. Pediatric Diabetes. 2011 Jun 23;12(4). doi: 10.1111/j.1399-5448.2011.00791.x

10. Ryan, RM \& Deci, EL. Self-determination theory and the facilitation of intrinsic motivation, social development, and well-being. American Psychologist, 2000; 55: 68-78.

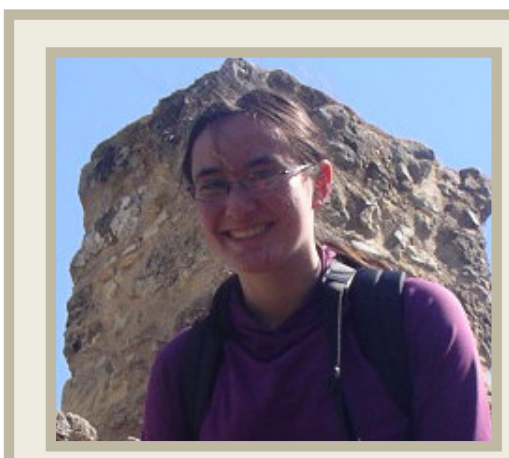

\section{Westerly Luth}

Westerly Luth is currently a Master's student in the School of Public Health at the University of Alberta. Her research interests are messaging in video games and science communication. Her recreational interests include video games, archery and knitting. 